\title{
Pregnancy Outcome after Multifoetal Sac Reduction to Twin in Higher Order Multiple Pregnancies.
}

\author{
MOSAMMAT RASHIDA BEGUM ${ }^{1}$, MARUF SIDDIQUI ${ }^{2}$, FARZANA KHAN ${ }^{3}$, MOSAMMAT SHAINA \\ BEGUM $^{3}$, HOSNE ARA BABY $^{4}$, EHSAN QUADIR ${ }^{5}$
}

\begin{abstract}
:
Objective: The aim of the study was to evaluate maternal and foetal outcome after fetoreduction in higher order multiple pregnancy.

Materials and methods: This descriptive study was conducted at the Infertility Care and Research Centre (ICRC), Dhaka between 2006 and 2009. In eleven (11) cases, multifoetal pregnancy reduction (MFPR) were performed and maternal and foetal conditions were analyzed. All patients got pregnant after fertility treatment. The procedure was done between 8-10 weeks of gestation except in one case which was done at 17 weeks. Transvaginal approach under spinal anaesthesia was adopted for intracardiac injection of potassium chloride till cessation of cardiac pulsation. Antibiotic, aspirin, antispasmodic and progesterone were used for all patients. Main outcome measures were uterine contraction, leaking membrane, bleeding, infection, abortion, gestational age and birth weight.
\end{abstract}

Results: Out of these eleven patients eight patients delivered twins at 37 weeks and one patient delivered a set of twin at 34 weeks and their antenatal period was uneventful. Two patients had abortions, one of which was not related with the procedure. No perinatal death was reported among 18 babies. Each of the babies born had an average weight of $2.42 \mathrm{~kg}$. There was no serious maternal complication except rise of temp in one patient.

Conclusion: Fetoreduction can improve the chances of survival and can reduce perinatal morbidity of remaining fetuses and can reduce maternal distress without any adverse affect to mother and foetuses.

Key words: Sac reduction, multiple pregnancy

\section{Introduction}

Recent advances in medical technology have succeeded in enabling couples who were previously considered infertile to conceive and to bear children. Through fertility drug treatment the risk of multifoetal pregnancy increases as a result of ovarian stimulation causing an increased production of ova. The procedure of in vitro fertilization often results in multifoetal pregnancy due to multiple implantations in an effort to increase the chance of successful outcome. Prior to the popularization of fertility treatments, the frequency of twin births was one in every ninety births

1. Assistant Professor(OBGYN), DMCH

2. Junior Consultant(OBGYN), OSD, DGHS, Deputed to BIRDEM

3. Infertility Care \& Research Center(ICRC)

4. Associate Professor(OBGYN), Enam Medical College, Savar

5. Assistant Professor(Paed), SSMCH in USA. By 1997, the frequency increased to one in 37 births. ${ }^{1}$ While the advances in assisted reproductive technologies are benefiting many couples who would otherwise be unable to bear children, the outcomes of fertility treatments may pose maternal and fetal risks. With the increasing number of fetuses, there is an increase in the risks of fetal anomalies, premature delivery, and spontaneous abortion.

In vitro fertilization is associated with multiple pregnancy because of the insertion of multiple fertilized eggs to increase the chance of successful implantation. Premature delivery is a risk associated with multiple pregnancy that increases the risk of infant morbidity and mortality. ${ }^{2}$ Potential maternal complications associated with multiple pregnancy are increased risk of pregnancy-induced hypertension, preeclampsia, polyhydramnios and severe anemia, as well as those general risks associated with long hospitalizations. ${ }^{3}$ Psychosocial disturbances to the mother are 
associated with the above mentioned risk factors that increases with multiple pregnancy, especially in light of the fact that many of the women who experience multiple pregnancy have undergone prolonged and emotionally distressing treatment for infertility.

First trimester multifoetal pregnancy reduction (MFPR) can be performed in order to decrease the risk of complications associated with multiple gestations. The procedure of multifoetal reduction has in recent year become both clinically and ethically accepted as a therapeutic option in pregnancies with four or more fetuses ${ }^{4-13}$. In case of triplet gestation, this option remains controversial $(4,10,11,13-17)$. With todays perinatal and neonatal care this outcome of triplets has improved considerably leading to low perinatal and neonatal mortality rate. Even then comparative studies showed better foetal outcome when triplets were reduced to twin in comparison to expectant management of triplets.

The procedure is invasive and not without risk. It may cause abortion and total foetal loss as well as maternal infections. So indications suggested by different researchers are

i) Four or more embryos ii) Triplets having serious maternal diseases, poor uterine conditions, previous caeserean section, $\mathrm{H} / \mathrm{O}$ previous preterm birth and embryo affected by serious diseases iii) Patient's request due to financial concern, mothers obligation to stop working, anticipating poor quality of life after birth of triplets and fear for distress during carrying triplets.

This descriptive study was carried out with an aim to evaluate maternal and foetal outcome after MFPR in multiple gestation more than two.

\section{Materials and methods:}

Study design and setting: This descriptive study was conducted at the Infertility Care and Research Centre (ICRC), Dhaka between 2006 and 2009.

Case selection and procedure : In eleven (11) cases, multifoetal pregnancy reduction were performed and maternal and foetal conditions were analyzed. All patients got pregnant after fertility treatment. Informed written consent was taken from all patients and their legal guardians. Patients were counseled regarding possibilities of abortion and maternal infection, bleeding and other rare complication like bleeding disorder. The procedure was done between 8-10 weeks of gestation except in one case which was done at 17 weeks, who had one anomalous foetus. Transvaginal approach through fornices under spinal anaesthesia was adopted for intracardiac injection of potassium chloride. Most accessible sac was targeted for reduction. In each foetus $1 \mathrm{ml}$ potassium chloride was injected into heart and needle was kept there till cessation of cardiac pulsation. No complication occurred during the procedure. Prophylactic antibiotic cefixime $200 \mathrm{mg}$ twice daily for 7 days, aspirin 75 mg daily till 34 weeks, antispasmodic tiemonium methyle sulphate $50 \mathrm{mg}$ thrice daily for 7 days and progesterone Inj Gestone (Ferring) $50 \mathrm{mg}$ daily for 20 weeks of gestation were used for all patients. Patients were monitored by USG weekly for first two weeks, monthly till 20 weeks and according to need afterwards. Coagulation profile was checked after two weeks of the procedure and in each month till 20 weeks of gestation. Main outcome measures were uterine contraction, leaking membrane, bleeding, infection, abortion, gestational age and birth weight.

\section{Results:}

Number of fetuses and their indications for reduction are given on table-I. Out of these eleven patients, eight patients had multiple gestations due to ART procedures while the remaining three patients had been treated with ovulation inducing drugs. Eight patients delivered twins at 37 weeks and their antenatal period was uneventful except one patient who suffered from leaking membrane and infection (table-II). One patient delivered twins at 34 weeks due to premature ruptured membrane. Unfortunately two patients had abortions, one was missed abortion. There was no perinatal death among 18 babies. Each of the babies born had an average weight of $2.42 \mathrm{~kg}$. There was no serious maternal complication except rise of temperature in one patient.

Table-I

Patients Characteristics

\begin{tabular}{lcc}
\hline Parameters & $\mathrm{N}$ & $\%$ \\
\hline Type of $R X$ & & \\
$\quad$ Ovulation induction & 3 & 27.27 \\
$\quad$ ART & 8 & 72.72 \\
$\begin{array}{l}\text { Number of foetus } \\
\quad \text { Quadruplets }\end{array}$ & 3 & 27.27 \\
$\quad$ Triplets & 8 & 72.72 \\
Indications & & \\
$\quad$ Quadruplets & 3 & 27.27 \\
$\quad$ Congenital anomalies & 1 & 9.09 \\
$\quad$ Intractable vomiting & 2 & 18.18 \\
$\quad$ Maternal desire & 5 & 45.45 \\
\hline
\end{tabular}


Table-II

Outcome of the procedure

\begin{tabular}{lcc}
\hline Outcome & $\mathrm{N}$ & $\%$ \\
\hline Abortion & 2 & 18.18 \\
Premature labour & 0 & 00 \\
Premature ruptured membrane & 1 & 9.09 \\
Delivery at 37 weeks (C/S) & 8 & 72.72 \\
Delivery at 36 weeks (C/S) & 1 & 9.09 \\
Uterine contraction, leaking & 1 & 9.09 \\
membrane and infection & \multicolumn{2}{c}{00} \\
Perinatal death & 0 & SD \\
Birth weight (kg) (Range) & Mean & 土.098 \\
& 2.42 & \multicolumn{2}{c}{ (2- 2.8 ) } \\
\hline
\end{tabular}

\section{Discussion:}

Multiple gestation present a significant increase in fetal growth abnormalities in direct relationship to the number of fetuses present. Healthy embryos are sacrificed in order to maximize the chances of survival of the remaining embryos or to allow the mother to choose the number of babies she wishes to deliver. Multifoetal pregnancy reduction reduces extreme prematurity before 32 weeks and improves foetal growth without excessive foetal loss. The ultrasonic prospective observation of expectantly managed triplet pregnancies reveals that fetal death is common before 24 weeks. Lipitz et al ${ }^{18}$ reported a spontaneous fetal loss rate among expectantly managed triplets of nearly $21 \%$ before 24 weeks. Kol et al. ${ }^{19}$ reports that spontaneous fetal death occurred in $5 \%$ of multiple pregnancies. These data suggest that the spontaneous loss rate in women carrying three fetuses may be similar to, or even higher than, the fetal loss rate observed following MFPR. Late MFPR at the midterm (20 weeks) could lead to a more favorable perinatal outcome. Delaying the procedure as late as 20 weeks may facilitate the detection of structural and chromosomal anomalies of the fetuses. However, studies are requested on larger series that should include only triplets with normal embryos in an effort to achieve homogeneity. Reducing qudruplets to twin has tremendous beneficial effect. There is debate about reducing triplets to twin but many researchers showed significant decrease in prematurity in reduced group. Lipitz et al showed $67.9 \%$ preterm births (36 weeks) among expectant group vs $16.1 \%$ among reduced group $^{20}$. Macones et al showed $43 \%$ birth before 32 weeks in non reduced triplets vs $4 \%$ in reduced twins $^{21}$. Other researchers ${ }^{22-24}$ suggested that a reduction from triplet to twin decreases the risk of extreme prematurity, and consequently that it may reduce the risk of cerebral palsy linked to intraventricular haemorrhage. Neonatal intensive care, ventilatory support and perinatal mortality was higher in non reduced triplets than reduced twins ${ }^{21,22}$. Bollen et $\mathrm{al}^{25}$ reported that $8 \%$ of surviving triplets suffer from neurological sequelae and this percentage may be higher because many of these infants were too young to permit full evaluation. Although MFPR decreases the number of babies going home per couple, it may increase the proportion of surviving infants without complications.

It should be noted, that MFPR on triplets is performed in several centres: in one study $42 \%$ of the 1084 procedures performed were for reducing triplets 26 . This rate is similar for a later expanded series including 1789 gestations out of which 759 were triplets ${ }^{27}$. In a French national study, $41 \%$ of 262 cases of reductions performed were on triplets ${ }^{28}$. Similar data are reported from monocentric series, with a mean rate of $24 \%$ 57.5\% 29-34. MFPR in triplets (resulting in twins and less often in singletons) should be considered in pregnancies with serious maternal disease (e.g. heart disease, diabetes), poor uterine conditions (bicornuate uterus, exposure to diethylstilboestrol, previous caesarean section, previous preterm delivery) or in cases where an embryo is affected by a severe disease (neural tube defect, cystic hygroma). In the absence of worrisome factors, one might consider that the decision belongs to the well-informed couple. The results shown above indicate that reduction of triplets improves some obstetric parameters. In addition psychological health and the relationship with the children were more satisfactory in the reduction grouping in comparison to non reduced group. Families with triplets had much more acute psychosocial problems than families who underwent MFPR.

In our series majority MFPR was done to reduce triplets. The indication of reduction is shown in table-l. Only three patients had quadruplets. In this report there were two abortions, one of which may not be procedure related because one foetus continued to grow till 14 weeks, thereafter died in the utero 6 weeks after the procedure. In other case gestational age was 17 weeks who had an anomalous foetus and 
fetoreduction was done for that reason. Abortion took place one week after the procedure. No other complications occurred in any other cases. Except one all patients delivered at 37 weeks of gestation. Only one delivered at 34 weeks due to premature ruptured membrane. No one had extreme low birth weight and birth asphyxia.

There was no serious maternal complication except rise of temperature in one patient, who had one anomalous baby. Five days after the procedure patient developed leaking membrane of existing sac and subsequently rise of temperature and uterine contraction. After addition of antibiotics temperature subsided but remaining two foetuses were expelled out. Though the number is very low in present study it gave us an impression of safety and rationality of the procedure.

\section{Conclusion}

The desire for a child is best fulfilled by a singletone or twin pregnancy rather than triplets or more. It seems that fetoreduction can improve the chances of survival and can reduce perinatal morbidity of remaining foetuses. Though number of cases are too small to draw any conclusion, we did not find any adverse affect after fetoreduction. It can reduce premature delivery and cost of intensive care and can reduce maternal distress of carrying three or more fetuses. So MFPR applied on higher order multiple pregnancies is a reasonable option of management and should be accepted if requested.

\section{References}

1. Wenger NS, DeCherney AH. An ethical approach to assisted reproduction. Reproductive Technologies 2000;10(4):178-183.

2. Antsaklis AJ, Drakakis P, Vlazakis GP, Michalas $S$. Reduction of multifetal pregnancies to twins does not increase obstetric or perinatal risks. Human Reproduction 1998;14:1338-1340.

3. Evans MI, Fletcher JC, Zador IE, Newton BW, Quiqq MH, Struyk CD. Selective first-trimester termination in octuplet and quadruplet pregnancies: clinical and ethical issues. Obstetrics and Gynecology 1988;71:289-296.

4. Berkowitz RL, Lynch, L, Chitkara U, et al. Selective reduction of multifetal pregnancies in the first trimester. N Engl J Med 1988;318:1043-1047.
5. Wapner RJ, Davis G, Johnson A et al. Selective reduction of multifetal pregnancies. Lancet 1990; 335:90-93.

6. Evans JI, Fletcher JC, Zador IE, et al. Selective first trimester termination in octuplet and quadruplet pregnancies: clinical and ethical issues. Obstet Gynecol 1988;71:289-296.

7. Lynch L, Berkowitz RL, Chitkara U, et al. First trimester transabdominal multifetal pregnancy reduction: a report of 85 cases. Obstet Gynecol 1990;75:735-738.

8. Evans MI, May M, Drugan A, et al. Selective termination: clinical experience and residual risks. Am J Obstet Gynecol1990;162:1568-1575.

9. Dommergues M, Nisand I, Mandelbrot L, et al. Embryo reduction in multifetal pregnancies after infertility therapy: obstetrical risks and perinatal benefits are related to operative strategy. Fertil Steril 1991;55:805-811.

10. Berkowitz RL, Lynch L, Lapinski R, Bergh P First trimester transabdominal multifetal pregnancy reduction: a report of two hundred completed cases. Am J Obstet Gynecol1993;169:17-21.

11. Timor-Tritsch IE, Peisner DB, Monteagudo A, et al. Multifetal pregnancy reduction by transvaginal puncture: evaluation of the technique used in 134 cases. Am J Obstet Gynecol 1993;168:799-804.

12. Evans MI, Dommergues M, Wapner RJ, et al. Efficacy of transabdominal multifetal pregnancy reduction: collaborative experience among the world's largest centers. Obstet Gynecol 1993; 82: 61-62.

13. Evans MI, Dommergues M, Timor-Tritsch I, et al. Trasnabdominal versus transcervical and transvaginal multifetal pregnancy reduction: international collaborative experience of more than one thousand cases. Am J Obstet Gynecol 1994; 170: 902-909.

14. American College of Obstetrics \& Gynecology. Multifetal pregnancy reduction and selective fetal termination ACOG Committee Opinion 94, April 1991.

15. Melgar CA, Rosenfeld DL, Rawlinson K, Greenberg M. Perinatal outcome after multifetal reduction to twins compared with nonreduced multiple gestations. Obstet Gynecol 1991; 78: 763-767. 
16. Porreco RP, Burjke MS, Hendrix ML. Multiple reduction of triplets and pregnancy outcome. Obstet Gynecol 1991;78:135-339.

17. Vauthier-Brouzes D, Lefebvre G. Selective reduction in multifetal pregnancies: technical and psychological aspects Fertil Steril 1992; 57: 1012-1016.

18. Lipitz, S., Reichman, B., Uval, J. et al. A prospective comparison of the outcome of triplet pregnancies managed expectantly or by multifetal reduction to twins. Am J Obstet Gynecol 1994; 170: 874-879.

19. Kol, S., Levron, J., Lewit, N. et al. The natural history of multiple pregnancies after assisted reproduction: is spontaneous demise a clinically significant phenomenon? Fertil Steril 1993; 60: 127-130.

20. Lipitz S, Reichman B, Paret G, et al. The improving outcome of triplet pregnancies. $A m \mathrm{~J}$ Obstet Gynecol 1989;161:1279-1284.

21. Macones, G.A., Schemmer, G., Pritts, E. et al. (1993) Multifetal reduction of triplets to twins improves perinatal outcome. Am J Obstet Gynecol 1993; 169: 982-986.

22. Bollen, N., Camus, M., Tournaye, H. et al. Embryo reduction in triplet pregnancies after assisted procreation: a comparative study. Fertil Steril 1993; 60: 504-509.

23. Boulot, P., Hedon, B., Pelliccia, G. et al. The effects of selective reduction in triplet gestations: a comparative study on 80 cases managed with or without this procedure. Fertil Steril 1993a; 60: 497-503.

24. Boulot, P., Hedon, B., Pelliccia, G. et al. Multifetal pregnancy reduction: a consecutive series of 61 cases. Br J Obstet Gynæcol.1993b;100: 63-68.

25. Bollen, N., Camus, M., Tournaye, H. et al. Embryo reduction in triplet pregnancies after assisted procreation: a comparative study. Fertil Steril 1993; 60:504-509.

26. Evans, M.I., Dommergues, M., Wapner, R.J. et al. Transabdominal versus transcervical and transvaginal multifetal pregnancy reduction: International collaborative experience of more than thousand cases. Am J Obstet Gynecol.1994; 170: 902-909.

27. Evans MI, Kramer RL, Yaron, Y. et al. What are the ethical and technical problems associated with multifetal pregnancy gestation? Clin Obstet Gynecol 1998; 41: 47-54.

28. Dommergues, M., Aknin, J., Boulot, P. et al. Réductions embryonnaires dans les grossesses multiples. Une enquête multicentrique franciaise. J Gynecol Obstet Biol Reprod 1994; 23: 415418.

29. Wapner, R.J., Davis, G.H., Johnson, A. et al. Selective reduction of multifetal pregnancies. Lancet 1990; 335: 90-94

30. Salat-Baroux, J., Aknin, J., Antoine, J.M. et al. The management of multiple pregnancies after induction for superovulation. Hum Reprod 1988; 3: 399-401.

31. Dommergues, M., Nisand, I., Mandelbrot, L. et al. Embryo reduction in multifetal pregnancies following infertility therapy: obstetrical risks and perinatal benefits are related to operative strategy. Fertil Steril1991; 55: 801-811.

32. Tabsh, K.A. Transabdominal multifetal pregnancy reduction: report of 40 cases. Obstet Gynecol 1990; 75: 739-741.

33. Timor-Tritsch, I.E., Peisner, B.D., Monteagudo, A. et al. Multifetal pregnancy reduction by transvaginal puncture: Evaluation of the technique used in 134 cases. Am J Obstet Gynecol1993; 168: 799-804.

34. Berkowitz, R.L., Lynch, L., Stone, J. et al. The current status of multifetal pregnancy reduction. Am J Obstet Gynecol1996; 174: 1265-1272. 